\title{
Overview of Paediatric Renal Care Activities and Availability of Renal Replacement Therapy for Children at Mulago Hospital, Uganda
}

\author{
Odiit Amos ${ }^{*}, 1$, Kalyesubula Robert ${ }^{2}$, Atukunda Peace ${ }^{3}$, Nabacwa Oliver ${ }^{3}$, S.P. Eyoku ${ }^{4}$ and \\ Kiguli Sarah ${ }^{1}$
}

\author{
${ }^{I}$ Department of Paediatrics \& Child Health, Faculty of Medicine, National University of Rwanda, P.O. BOX 117, \\ Butare, Rwanda \\ ${ }^{2}$ Department of Internal Medicine Makerere University, College of Health Sciences, P.O. BOX 7072, Kampala, Uganda \\ ${ }^{3}$ Department of Nursing, Mulago National Referral and Teaching Hospital, P.O. BOX 7051, Kampala, Uganda \\ ${ }^{4}$ Department of Internal Medicine, Mulago National Referral and Teaching Hospital, P.O. BOX 7051, Kampala, \\ Uganda
}

\begin{abstract}
Introduction: The range of activities undertaken by any renal team will depend on many factors. One of the common challenges encountered in Mulago hospital is management of kidney failure in a child.

Objective: to outline activities of the renal team with specific reference to RRT.

Methodology: members of the renal team were interviewed for their activities, and ward records spanning a period of 3 years were reviewed, for information on children who had had RRT.

Results: activities of the renal team included: training, sensitization of the public, research, and nursing care of patients on dialysis. Nineteen (19) children had had RRT, fourteen (14) had been put on PD; 4 on Haemodialysis (HD); and 1 child had a kidney transplant in India. All children with Acute Tubular Necrosis recovered normal kidney functions by the end of RRT; 3 out of the 4 children with rapidly progressive Glomerulonephritis progressed to CKD.
\end{abstract}

Conclusion: Renal Replacement Therapy for children is happening at a very low level. The renal team is engaged predominantly in conservative management of kidney failure and in preventive activities.

Keywords: In a resource poor country, renal care for children.

\section{INTRODUCTION AND BACKGROUND}

Over the last 10 years there have been openings for hospitals in resource poor countries in Africa, including Uganda to improve their clinical services through training in Paediatric Nephrology and other sub-specialties. This has been achieved through clinical attachments to centres of excellence, within and outside Africa. The range of paediatric renal care activities that the renal team engages in will vary according to availability of resources. The commonest clinical challenge to the renal team is management of a child who is in kidney failure.

Kidney failure is part of the continuum of Acute Kidney Injury (AKI), in which serum creatinine and urea will have risen above normal limits. One or the other form of Renal Replacement Therapy may need to be employed to support the body during the period of kidney failure [1].

*Address correspondence to this author at the Department of Paediatrics \& Child Health; Faculty of Medicine; National University of Rwanda, P.O. BOX 117, Butare, Rwanda; Tel: 256025641454 1589;

E-mail: amosodiit@hotmail.com
That AKI occurs quite commonly among children in resource poor settings is attested to by publications from Congo Brazzaville [2] among others. A previous study at the Mulago hospital showed that there was at least 1 child per week with kidney failure and that while a majority of children with AKI improved, a quarter of them would subsequently require a form of RRT [3]. The capacity to perform dialysis has been growing steadily in Mulago hospital: with 3 nephrologists, 5 renal nurses, 1 vascular surgeon, 1 general surgeon, and 6 Haemodialysis machines. Creation of fistulae for vascular access is on the rise in support of Haemodialysis as a form of RRT. Peritoneal dialysis catheters are usually surgically placed in the bid to avoid peritonitis as much as possible. In the peritoneal dialysis program in Sudan [4], nearly a fifth of the children who had been started on peritoneal dialysis had to be changed to haemodialysis, underscoring the importance of having all the forms of RRT in the centre.

The main objective of this study was to present an overview of the activities of the paediatric renal team, focusing on availability of RRT for children in a tertiary and teaching hospital in Uganda. Waiver of consent and permission to use patient data was obtained from the Ethics and Research Committee of Mulago hospital. 
Table 1. Activities of the renal team, 2011 (summary).

\begin{tabular}{|c|c|}
\hline Activity & Comment \\
\hline \hline $\begin{array}{c}\text { Outpatient care of children } \\
\text { with kidney diseases }\end{array}$ & $\begin{array}{c}\text { A clinic once a week: average 13 cases/week, 3 being new. Common cases at out-patient clinic: CKD, Nephrotic } \\
\text { syndrome, follow up of AKI, Obstructive uropathies and renal anomalies. }\end{array}$ \\
\hline $\begin{array}{c}\text { In-patient care of children } \\
\text { with kidney diseases }\end{array}$ & Daily admissions from the Paediatric Acute Care Unit: 240 in 2011. Ten to 20 cases of severe renal failure per month \\
\hline Research & $\begin{array}{c}\text { 'Prevalence of AKI among children with severe acute infections; and effect of AKI on mortality rates'.... on-going } \\
\text { 'Micro-albuminuria among Sickle cell anaemia' \& 'micro-albuminuria among type 1 diabetes children'... done }\end{array}$ \\
\hline Preventive & Early detection of Nephropathy in children with type 1 Diabetes Mellitus. Health education talks... on-going \\
\hline $\begin{array}{c}\text { Public sensitization on } \\
\text { kidney diseases }\end{array}$ & Seminars, Radio \& Television talk shows (Kampala renal week [5], World Kidney days). \\
\hline $\begin{array}{c}\text { Participation in training } \\
\text { Undergraduate \& Post graduate medical training programs at Makerere University College of Health Sciences; and in- } \\
\text { service training of health workers. }\end{array}$ \\
\hline
\end{tabular}

\section{METHODS}

Information about activities of the renal team was obtained by asking the members of the team to list their activities that were linked to renal care in the year 2011.

Review of records at the dialysis unit (ward 6), for a period of 3 years $(2009,2010,2011)$, was done. Dialysis was considered as having been performed in a child if the clinician's notes contained the description of the process of catheter insertion (peritoneal or venous), and if the notes showed a record of fluid exchanges or haemodialysis cycles. The diagnosis or diagnostic category was taken to be that stated in the patient's case notes, if supported by investigations and clinical course. Nursing notes and laboratory results were scrutinized for the patients' response to treatment. Outcome of a patient's treatment was recorded as: complete recovery if the patient improved clinically and serum creatinine fell to $<1 \mathrm{gm} / \mathrm{dl}$. Patient information was recorded in a pre-coded questionnaire which included sociodemographic characteristics, serum creatinine, urea and electrolytes; cause and duration of kidney failure; the reason for RRT and the type of RRT. Any patient whose records of identification, serum creatinine levels and RRT were inconsistent or incomplete was excluded.

\section{RESULTS}

At the dialysis unit, nurses who were trained at the centres of excellence provide nursing care to patients on haemodialysis while the patients on peritoneal dialysis were being managed by nurses who were locally trained.

Each Nephrologist (out of 3 ) had designated lectures and other academic sessions to both undergraduate and postgraduate students. Each Nephrologist had delivered at least 1 public awareness session on kidney diseases over a period of 1 year. All Nephrologists had been involved in at least one research on kidney disease within the last 1 year, and were involved in chronic care of patients with kidney diseases at the hospital clinic.

Nineteen children received one or the other form of Renal Replacement Therapy over the period of 3 years. Fourteen were put on Peritoneal Dialysis: nine female, and 5 male. Age range was 7 months to 15 years by start of peritoneal dialysis; the median age being 7 years (range 0.6 -
15 years). The diagnoses for the children on PD were: Rapidly Progressive Glomerulonephritis (RPGN); Acute Tubular Necrosis (ATN); Chronic Kidney Disease (CKD); HIV associated nephropathy (HIVN); Haemolytic-Uraemic Syndrome (HUS).

Of the children with Acute Tubular Necrosis, two had Sickle Cell Anaemia with sepsis, while the other three had malaria complicated by massive intravascular haemolysis (black water fever).

Over the period reviewed, four children were put on haemodialysis: 18 and 15 year old girls, both with End Stage Renal Disease (ESRD) and severe hypertension (still dialyzing 1 year after onset of dialysis); 13 year old boy with Rapidly Progressive Glomerulonephritis (passed away on day 2 of HD; and a 16 year old boy with obstructive uropathy still on dialysis 1 year after initiation.

Table 2. Outcome of children who received RRT $(n=19)$.

\begin{tabular}{|c|c|c|c|}
\hline $\begin{array}{c}\text { Diagnostic } \\
\text { Category (n) }\end{array}$ & $\begin{array}{c}\text { Recovered Normal } \\
\text { Kidney Function (n) }\end{array}$ & $\begin{array}{c}\text { Progressed } \\
\text { to CKD (n) }\end{array}$ & $\begin{array}{c}\text { Died } \\
\text { (n) }\end{array}$ \\
\hline \hline RPGN (4) & 0 & 4 & 1 \\
\hline ATN (5) & 5 & 0 & 0 \\
\hline HIVN (2) & 0 & 0 & 2 \\
\hline HUS (2) & 0 & 1 & 1 \\
\hline CKD (6) & 0 & 6 (already CKD) & 2 \\
\hline
\end{tabular}

Only 1 child, 16 years of age, with CKD had received a kidney transplant over the review period. The transplant was done in India, at Apollo hospital, using a living related donor.

\section{DISCUSSION}

The activities for the renal team are many; touching outpatients, in-patients, students, and the general public. The list of activities is devoid of tasks that require a little more sophistication, like kidney transplantation.

Nineteen children received Renal Replacement Therapy from January 2009 to February 2012. Though there was no 
documentation of the total number of children who needed dialysis over the same period, a total of 19 children in 3 years represents very low access to RRT in a hospital which admits 10-15 severe renal failure children per month. Low dialysis access for children in Africa has been reported in Southern Nigeria [6] where only $24 \%$ of children who needed dialysis received it; and in Ghana [7] where dialysis was accessible only to $10 \%$.

Of the 19 children who received RRT 14(74\%) received Peritoneal Dialysis. The children who got haemodialysis $(n=4)$ over the period of 3 years were far fewer, and older than those who received PD. This difference is explained by the challenges of vascular access for HD, particularly in the younger children.

Haemodialysis tended to be the RRT of choice for children presenting with $\mathrm{CKD}$, while $\mathrm{PD}$ was used more commonly for any child coming in with AKI. Although establishment of acute forms of dialysis may be feasible in developing countries [8] Chronic RRT in form of long term dialysis and kidney transplantation is currently out of reach to most children who need it; yet it is estimated that the prevalence of CKD is at least 3 times higher in the subSaharan Africa than in developed countries [9].

Chronic Kidney Disease therefore poses a huge clinical challenge because the number of children with CKD keeps increasing, given that a percentage of AKI children keep joining the CKD group. As glomerular filtration rate continues falling, children with CKD enter into End Stage Renal Disease (ESRD) whose most preferable mode of management; kidney transplantation is much less available in resource poor countries [10]. In this review, only 1 child had had a kidney transplant, which had been done in India. The choice of which country a kidney transplant can be done is governed largely by costs, India being the most affordable from our local perspective. Post transplant kidney care is compounded by local inability to assay blood levels of immune-suppressive drugs.

\section{STUDY LIMITATIONS}

The retrospective nature and the low number of children who received RRT.

\section{CONCLUSION}

The renal team is involved in a range of activities; availability of RRT for children at Mulago hospital is very low.

\section{CONFLICT OF INTEREST}

The authors confirm that this article content has no conflict of interest.

\section{ACKNOWLEDGEMENTS}

We wish to acknowledge institutions and persons who contributed to training of the kidney care team at Mulago Hospital: Professor Mignon McCulloch; Professor Finkelstein; renal team of Kenyatta National Hospital; the International Society of Nephrology, and the International Paediatric Nephrology Association.

\section{REFERENCES}

[1] Becker BN, Stone WJ. Options for renal replacement therapy: special considerations. Semin Nephrol 1997; 17 (3): 176-87.

[2] Assounga AG, Assambo-Kieli C, Mafoua A, Moyen G, Nzingoula S. Aetiology and outcome of Acute Renal Failure in children in Congo Brazzaville. Saudi J Kidney Dis Transpl 2000; 11: 40-3.

[3] Odiit A. Renal Failure outcome among Paediatric admissions where renal replacement therapy is inaccessible. Poster presentation at International Congress of Nephrology at Rio de Jeneiro, 2007.

[4] Elhassan Elwaleed AM, Kaballo B, Fadail H, et al. Peritoneal dialysis in Sudan. Perit Dial Int 2007, 27; 5: 503-10.

[5] Kalyesubula R, Odiit A, Carter M, et al. A time to improve kidney care and awareness in Uganda. Dialysis times, News Views Renal Res Inste 2012; 19(2): 1-4.

[6] Anochie C, Eke FU. Paediatric acute peritoneal dialysis in South Nigeria. Postgrad Med J 2006; 82 (965): 228-30.

[7] Antwi S. dspace.Knust.edu.gh:8080/jspui/bitstream/123456789/... ....mc $\% 201 \mathrm{pd}$.

[8] Callegari J, Kilonzo GK, Yeates KE, et al. Peritoneal dialysis for acute kidney injury in sub-Saharan Africa: challenges faced and lessons learned at Kilimanjaro Christian Medical Centre. Kidney Int 2012, 81: 331-3.

[9] Naiker S. End-stage renal disease in sub-Saharan Africa. Ethn Dis 2009; 19 (Suppl 1): S1-13.

[10] Warady BA, Chadha V. Chronic kidney disease in children, the global perspective. Pediatr Nephrol 2007; 22(12): 1999-2009. 